\title{
Therapie und Sie
}

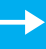

Vielleicht haben Sie es schon beim Blick auf das Cover bemerkt? Alles ein bisschen anders, aber nicht komplett neu. Wir haben physiopraxis für Sie modernisiert. Wir haben nicht nur unser Layout luftiger und moderner gestaltet, Sie finden nun auch noch mehr Therapiethemen in jeder Ausgabe. Wie gewohnt in einer Mischung aus neuen Erkenntnissen, Handlungsanweisungen, Hintergründen, Updates und evidenzbasierten Therapieansätzen zu den Themen Untersuchen, Behandeln, Evaluieren und Dokumentieren.

Bei unserem Titelthema geht es diesmal beispielsweise um die richtige Orthesenversorgung (ab Seite 26). Leitlinien empfehlen deren Einsatz und aktives Training für ein sichereres Gangbild. Wir zeigen Ihnen, wie Sie Ihren Patienten bei der Auswahl helfen können. Und ab Seite 36 wartet wieder ein spannender Fall auf Sie. Drei Experten erläutern, wie sie einen Fußballer wieder auf die Beine bringen, den ein Ball so unglücklich am Kopf traf, dass er einige Sekunden bewusstlos war und mit einem Beschleunigungstrauma zur Physiotherapie kommt.

Neu sind unsere „Community-Seiten“ (ab Seite 6). Denn in Zeiten von Facebook und Co erreicht uns Spannendes aus der Physiowelt nicht mehr nur als klassischer Leserbrief. Ihre Statements, Fotos, Videos, Tipps... alles, was Sie gerne mit Ihren Kollegen beruflich teilen wollen, findet hier Platz - Ihre Seite zum Austauschen.

Ich freue mich auf Ihre Beiträge per Mail oder auf unserer Facebook-Seite „Thieme liebt Physiotherapeuten “ und wünsche Ihnen ein zufriedenes Jahr 2016!

Herzlichst, Ihre

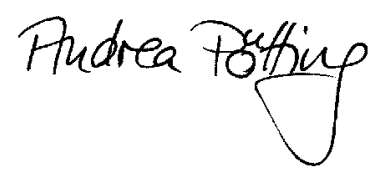

PS: Nicht neu, sondern seit zehn Jahren bewährt - das ist der physiokongress. Ein spannendes Programm umrahmt von einer Therapiemesse mit über 140 Ausstellern. Dieses Jahr vom 29.-31. Januar in Stuttgart. Ich hoffe, wir sehen uns dort. Noch gibt es Karten.

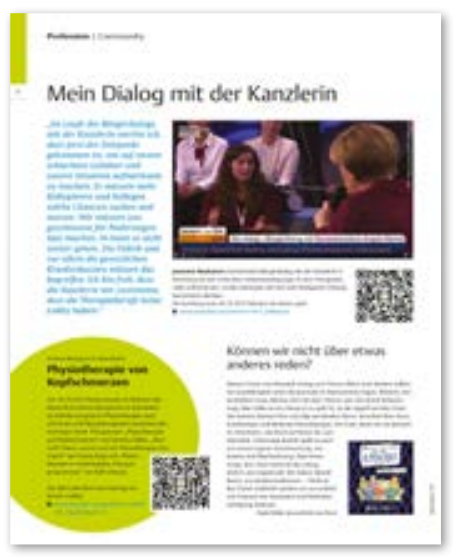

Welche Physiotherapeutin sprach mit der Kanzlerin? Was gab's Spannendes auf dem Schmerzkongress? Dies und mehr finden Sie ab jetzt in „Community“. 